\title{
Psychological Capital of Nurses Working in Academic Medical Centers of Iran University of Medical Sciences
}

\author{
Ezzat Jafar Jalal $^{1}$, Naima Seyedfatemi ${ }^{2}$, Shima Haghani ${ }^{3}$, Masoud Feyzbabaie ${ }^{4}$
}

\begin{abstract}
Background \& Aims: Nursing, the core and front line of the health system, is considered as one of the most challenging jobs due to problems such as lack of human resources, increasing demand in the clinical environment, constant changes in work schedule, client expectations, legal problems, and client mortality. Paying attention to influential factors including client health is important in creating a positive working environment and increasing the mental health of nurses. One of the issues raised recently is psychological capital, with four dimensions of self-efficacy, optimism, hope, and resilience. Psychological capital has a positive effect on work attitude and behavior and is positively related to constructive performance. In addition, psychological capital leads to better psychological health, better adaptation to stressful conditions, and increases nurses' ability to cope with the problems. Given that nurses are always exposed to physical, mental, and emotional challenges, hospital managers should provide mechanisms to reduce potential workplace risks. Recognition of preventive factors (e.g., psychological capital) is the first step towards the growth and development of effective policies in this area. Therefore, this study was conducted to determine the psychological capital of nurses working in academic medical centers of Iran University of Medical Sciences.

Materials \& Methods: This descriptive study was conducted to examine the psychological capital of nurses working in academic medical centers of Iran University of Medical Sciences in 2019. The study population was all nurses working in academic medical centers affiliated to Iran University of Medical Sciences in 2019 and the sample included 305 nurses with inclusion criteria (at least 1 year of clinical experience and not facing severe crises or death of loved ones during the last 6 months) from emergency departments, pediatric ward, ICU, CCU, internal ward, psychiatric ward, Operating room, obstetrics ward, surgical ward, dialysis unit, burn unit, oncology, and etc. Sampling was performed using proportional allocation procedure and samples were selected from academic medical centers of Iran University of Medical Sciences. The Psychological Capital Questionnaire devised by Luthans was used to collect the data. The questionnaire Includes 24 items in 4 subscales of hope, selfefficacy, resilience, and optimism, and is scored based on 6-point Likert scale ranging from 1 (strongly disagree) to 6 (strongly agree). Its score ranges from 24 to 144, with a higher score indicating a higher level of psychological capital. The Demographics Survey included information such as age, gender, marital status, employment status, education, work experience, income, employment in one or more hospitals, experience in the current ward, work experience in current hospital, job position, shift work. Sampling and collecting questionnaires took about 5 months (from October 2019 to March 2020) as the nurses were too busy. Data analysis was performed using SPSS software version 16. Descriptive statistics and inferential statistics were used to analyze the data. In the descriptive statistics part, frequency distribution tables were used to analyze the qualitative variables of the research and numerical indices of minimum, maximum, mean, and standard deviation were used to analyze the quantitative variables of the research. In inferential statistics part, Pearson correlation coefficient, independent t-test, ANOVA, and multiple linear regression model were used.

Results: The mean age of the subjects was 34.75 with a standard deviation of 7.71 years. $86.9 \%$ of the nurses were female and $86.6 \%$ had an undergraduate degree. Most nurses were married $(55.4 \%)$. The economic status of $78.7 \%$ of the nurses was average and $89.8 \%$ of them did not report any specific chronic disease. $49.8 \%$ of the nurses were employed. The morning shift accounted for $63.3 \%$ of the work shift. The majority of participants

\footnotetext{
1. Community Health, Nursing Management Department, School of Nursing and Midwifery, Iran University of Medical Sciences, Tehran. Iran

${ }^{2}$. Nursing Care Research Center, Psychiatric Nursing Department, School of Nursing and Midwifery, Iran University of Medical Sciences, Tehran, Iran

${ }^{3}$. Nursing Care Research Center, School of Nursing and Midwifery, Iran University of Medical Sciences, Tehran, Iran ${ }^{4}$. Psychiatric Nursing Department, School of Nursing and Midwifery, Iran University of Medical Sciences, Tehran, Iran (Corresponding author) Tel: 09392687559 Email: fbmasoud7292@gmail.com
} 
were nurses (85.2\%). Most of the participating nurses were working in intensive care units (38\%). The average work experience of all participants was $10.44 \pm 6.96$. Their average work experience in the current wards was $4.82 \pm 4.41$ and also the average work experience in the current hospital was $8.26 \pm 6.20$. The results revealed that the mean of psychological capital was $104.63 \pm 15.25$, and given the score range of 24-144 in the Psychological Capital Questionnaire and the mean score, it can be concluded that nurses had a high level of psychological capital. Among the components of psychological capital, the highest mean score was related to self-efficacy of $28.29 \pm$ 4.70 and the lowest mean score was related to resilience of $24.62 \pm 4.37$. Also, psychological capital had a statistically significant relationship with job position $(\mathrm{P}<0.001)$ and chronic disease $(\mathrm{P}=0.050)$. Tukey's multiple comparison showed that the mean score obtained for psychological capital of nurses was significantly lower than the one obtained for head nurses $(\mathrm{P}=0.002)$ and supervisors $(\mathrm{P}=0.029)$. It was also observed that the average score of psychological capital in nurses with chronic diseases was significantly lower than others. It should be noted that other personal and occupational variables had no statistically significant relationship with psychological capital.

Conclusion: According to the mean scores obtained from this study, it can be said that nurses have an almost high level of psychological capital and the highest mean score among the dimensions of psychological capital was related to self-efficacy. Regarding the correlation of research variables with demographic characteristics, the results showed that the psychological capital of nurses was less than that of head nurses and supervisors, which increases the importance of addressing psychological capital in nurses. It is possible to provide the basis for improving their personal, professional, and caring performance by focusing on psychological capital in nurses and adopting proper planning for necessary training in this field. Considering that the resilience component of the psychological capital variable obtained the lowest average, paying attention to this component in nurses is of great importance. We can also point out the importance of these variables and their impacts on personal, occupational, and organizational areas, including personal and psychological effects and care outcomes such as improving the quality of care and organizational outcomes, which increases the importance of paying attention to it.

\section{Keywords: Psychological Capital, Nurses}

\section{Conflict of Interest: No}

How to Cite: Jafar Jalal E, Seyedfatemi N, Haghani SH, Feyzbabaie M. Psychological Capital of Nurses Working in Academic Medical Centers of Iran University of Medical Sciences. Iran Journal of Nursing. 2021; 34(129): 27-38.

Received: 6 Jan 2021

Accepted: 7 Apr 2021 


\title{
سرمايه روانشناختى برستاران شاغل در مراكز آموزشى درمانى دانشكاه علوم يزشكى ايران
}

\author{
عزت جعفر جلال '، نعيمه سيد فاطمى '، شيما حقانى '، مسعود فيض بابايىع
}

\begin{abstract}
جكيu.

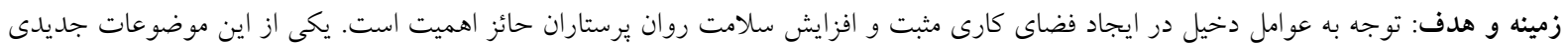

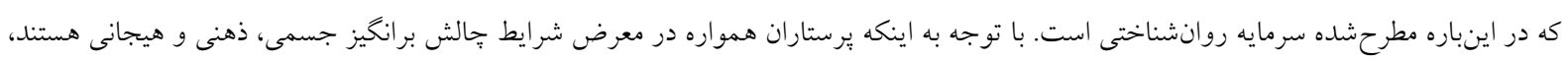

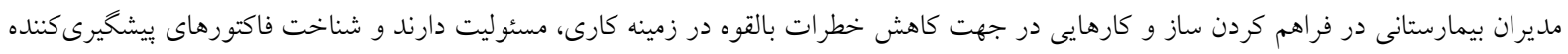

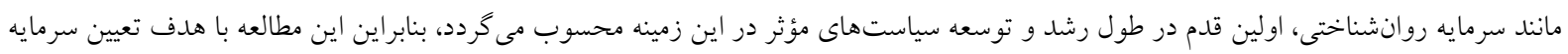

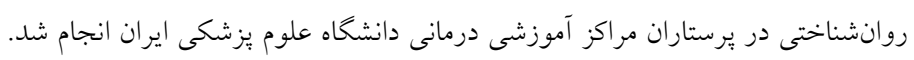

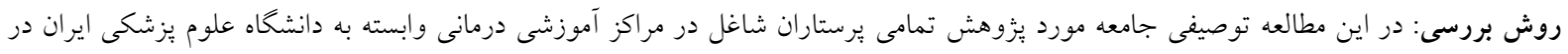

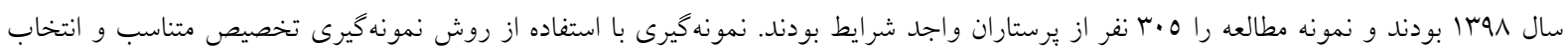

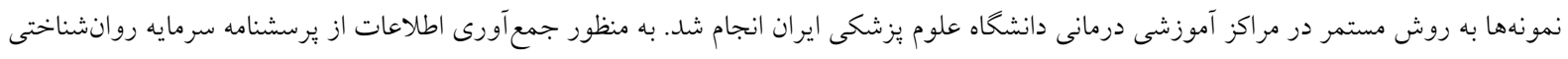
Luthans

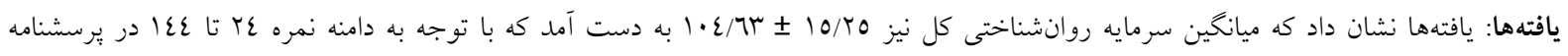

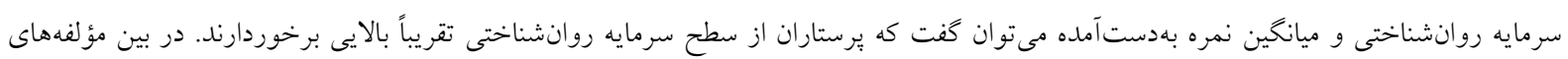

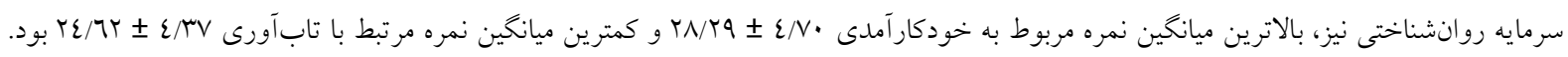

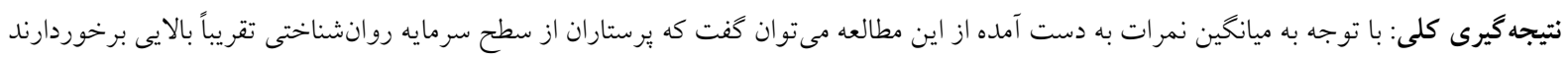

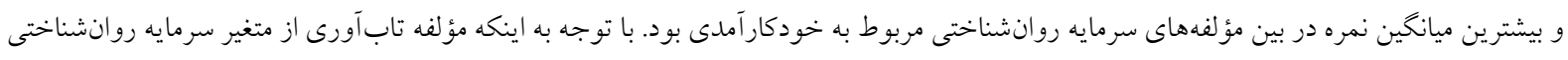

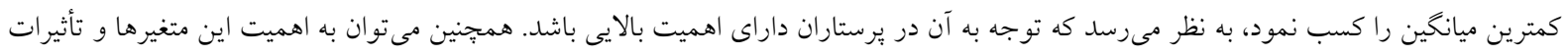

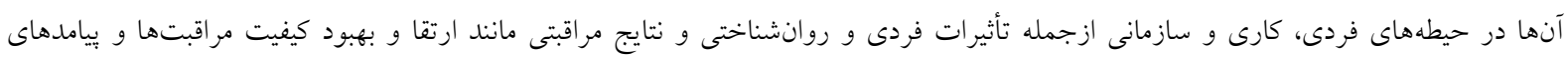

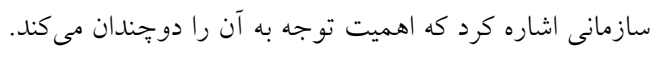

كليد وازهها: سرمايه روانشناختى، برستاران

تعارض منافع: وجود ندارد.

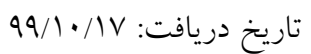

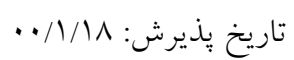

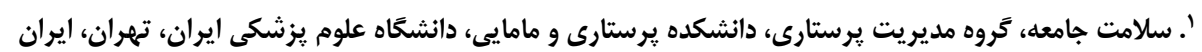

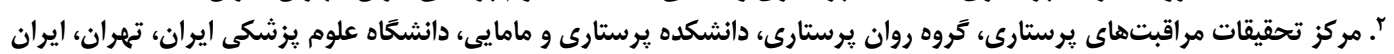

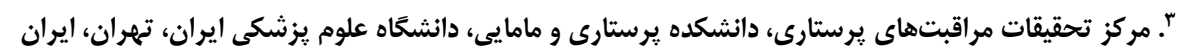

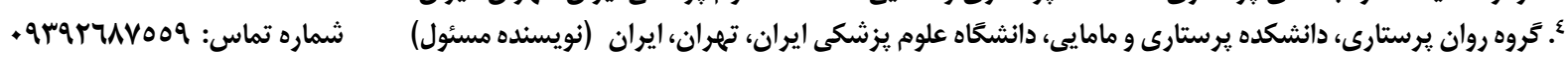


هشتكار به خرج دادن در مسير اهداف، و در صورت لزوم

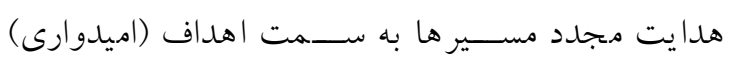

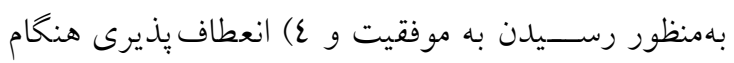
احاطه شدن تو سط مشكلات و خطرها جهت دستيابى به به ونه

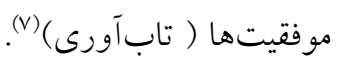
وقتى كه صــحبت از محيط كارى مى شـــود، محققين بيان مى كنند كه سرمايه روان شناختى تأثير مثبتى از نظر نخرش

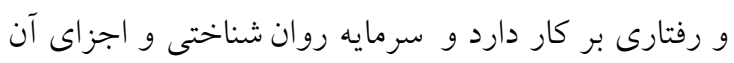
به طور مثبتى با عملكرد سازنده مرتبط هـستند (^). سرمايه وايه

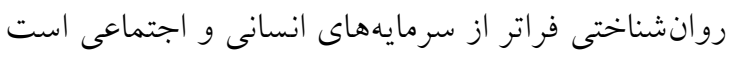
كه مى تواند روى متغيرهاى فردى و ســازمانى مانند رفتار

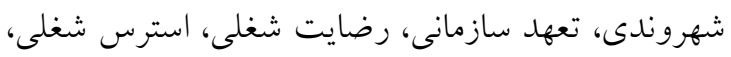

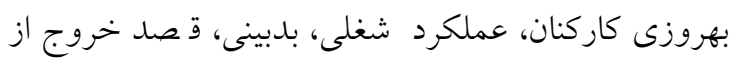

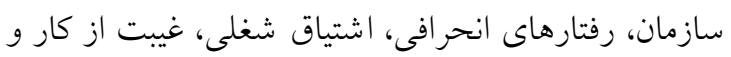

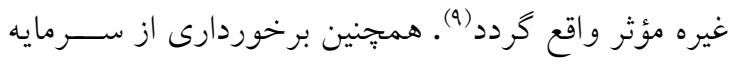

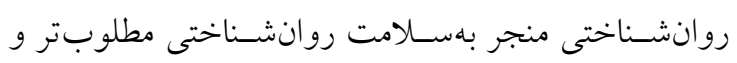

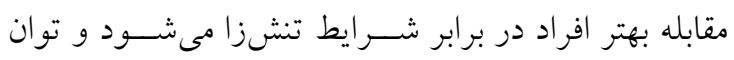

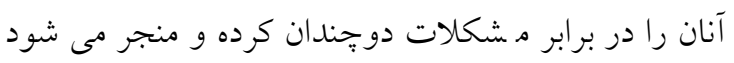

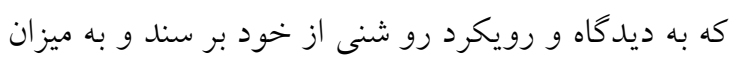

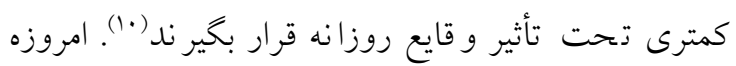
توجه به اهميت مديريت سرمايه روانشناختى به اين دليل

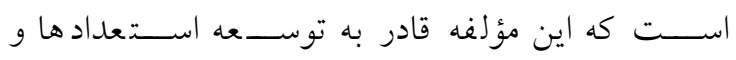

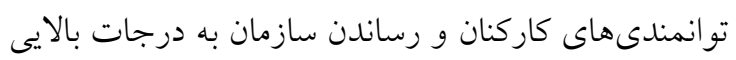

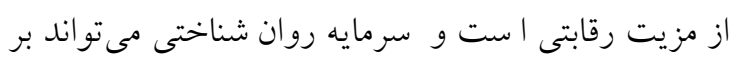

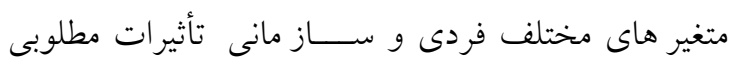

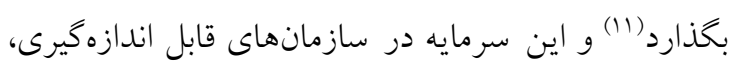
توسعه و برورش است كه امكان اعمال مديريت بر آن نيز وجود دارد) اما در حيطه حرفه يُر ستارى، سرمايه روان شناختى بالا در

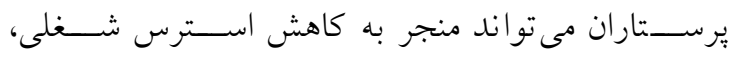

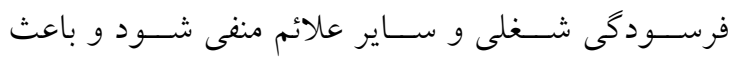

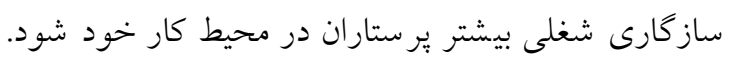

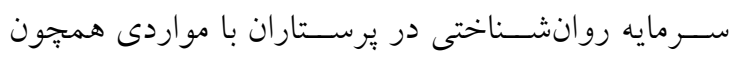

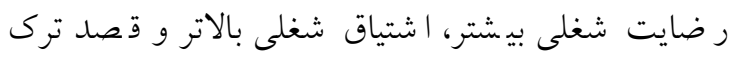

\section{مقدمه}

يرســتاران بهعنوان بزرگترين گروه ارائهدهنده خدمات مراقبت در مان داراى نيروى بالقوه قابل توجهى در ارائه مراقبتهاى بهدا شتى با كيفيت بالا هـ ستند كه اين نيرو بر كيفيت مراقبتهاى ارائه شده تو سط آنان تأثير مى گذارد (1). اين حرفه به عنوان هسته اصلى و خط مقدم نظام سالات،

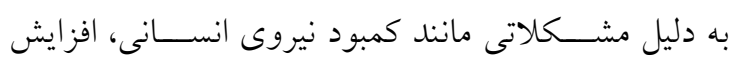
تقاضــــا در محيط بالينى، تغييرات مداوم روتين كارى، انتظارات مددجو يان و مشــكلات قانونى و مرگ و مير مددجويان بهعنوان يكى از جالش برانخيزترين شغل ها در نظر كرفته مىشـــود و يرســـار ان همواره با مشـــكلات عمدهاى در زمينه سـالامت روانى مانند اسـترس شــلى، فر سودگى، اضطراب و اف سردگى روبرو هـ ستند (r،ب). اين كمبودها و مشـــكلات همراه با بير شــــن نيروى كار و افزايش ميزان قصد ترى شغلى همراه بوده كه در سالهاى اخير رو به شـــت كذاشــه و تهلديدكننده توانايى نيروى كارى ير ستارى است (ع). بنابراين توجه به عوامل دخيل در بهر ايجاد فضاى كارى مثبت و افزايش سلامت روان برستاران،

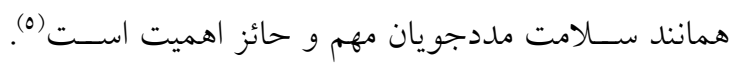
براى تحقق اين موضـــوع، راهبردهاى مختلفى از ســوى

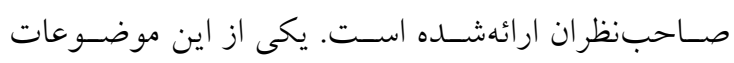
جديدى كه در اين باره مطرح شده سرمايه روان شناختى اســـت كه طلايهدار آن (Psychological Capital) Fred Luthans روان شناختى رشدى مثبت كه بر توانمندىها و داشتههاى فرد تأكيد دارد و به موضوعات مثبت زندگى افراد ازجمله بهزيســـى، شـــــادكـامى، هوش هيجــانى، خردمنـــى،

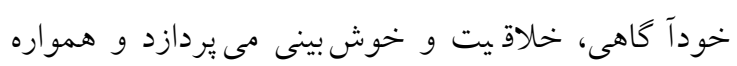
سعى دارد با يك ديدگاه علمى و عملى، حضور اين جنين

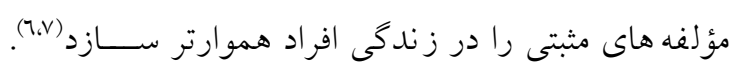

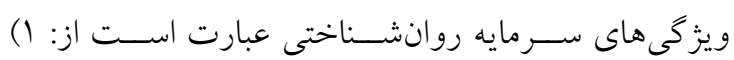

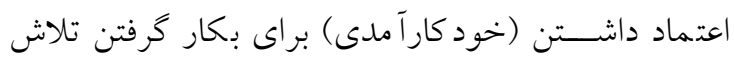
كافى بهمنظور موفقيت در وظايف جالشبر انخيز، ب) ايجاد

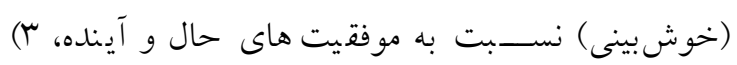


ايران در سال هوبا بودند و نمونه مطالعه را ه.r نفر از يرستاران واجد شرايط و داراى ملاكهاى ورود به مطالعه

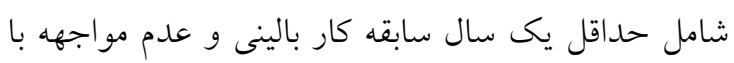

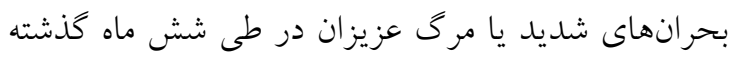

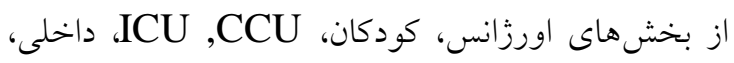

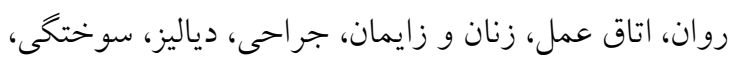

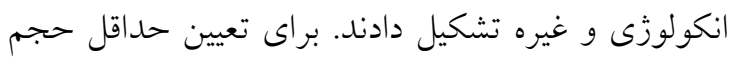

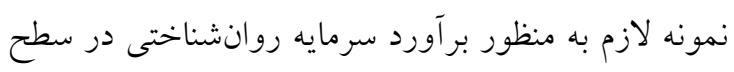

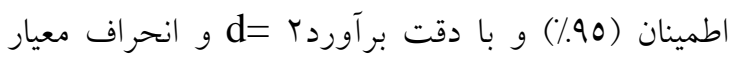

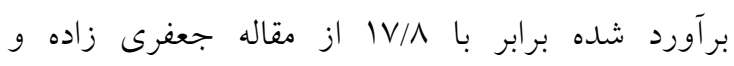

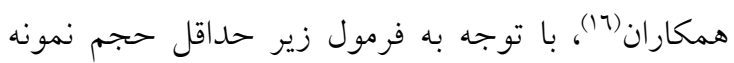

$$
\text { لازم 0. انفر برآورد كرديد. }
$$

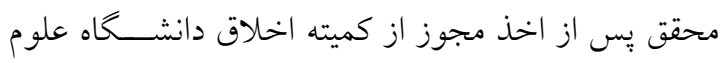

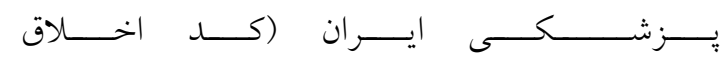

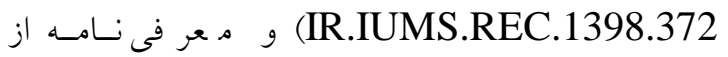
دانشــكده برســتارى و ما مايى و ارائه به مســـــولان بيمارسـتان هاى منتخب و ســـس معرفى خود و ارائه

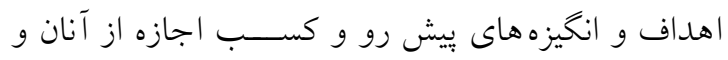

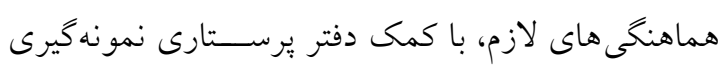

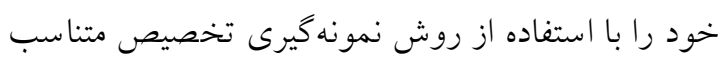

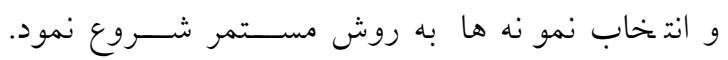

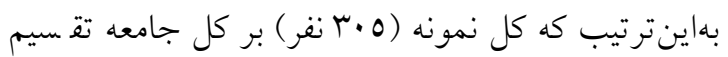

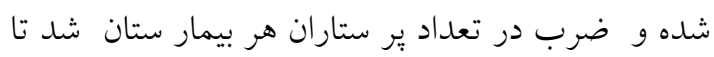

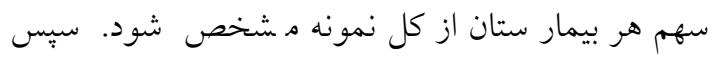

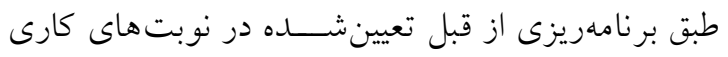

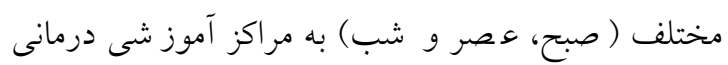

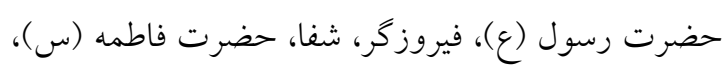

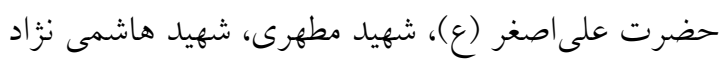

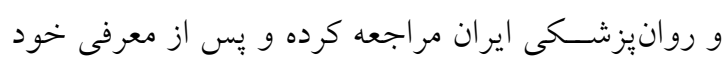

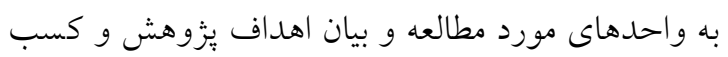

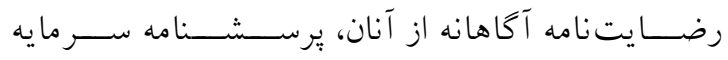
روان شناختى luthans را به همراه ير سششنامه اطلاعات

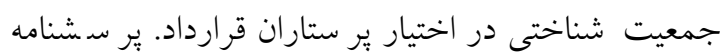
مشخصات جمعيت شناختى شامل سن، جنس، وضعيت
شـــلى كمتر همراه اســـت كه مىتواند منجر به ابقاى

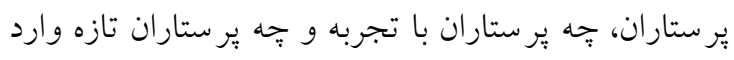

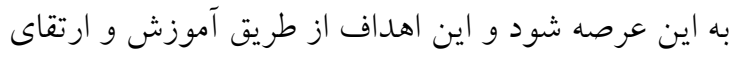

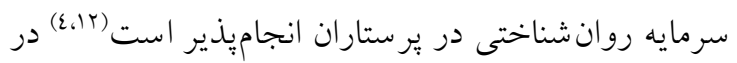
مطالعه Idris and Manganaro يافتهها نشــان داد كه بهبود در ســـرمايه روانشــناختى مثبت مىتواند منجر به

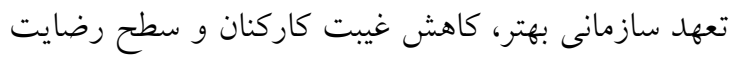

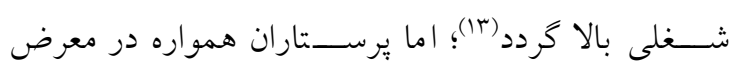

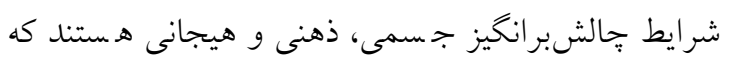

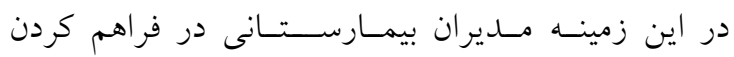
ســازو كارهايى در جهت كاهش خطرات بالقوه در زمينه

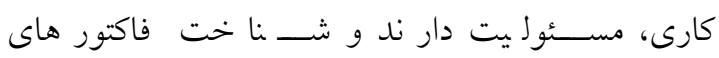

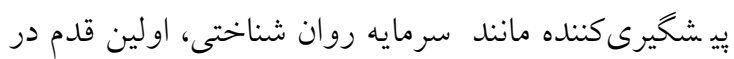

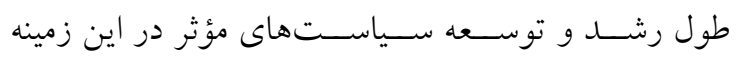

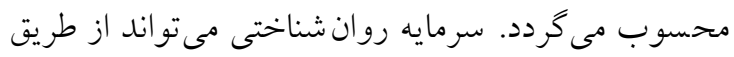

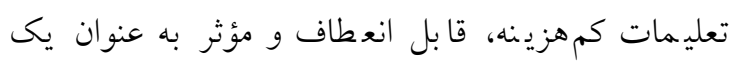

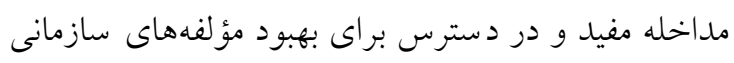

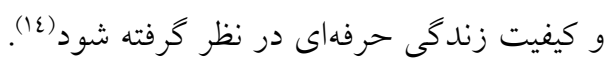

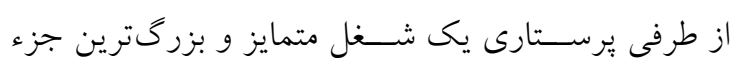

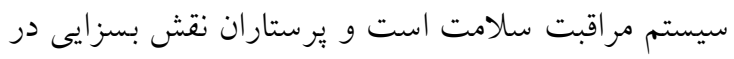

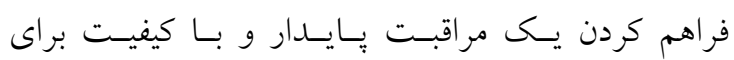

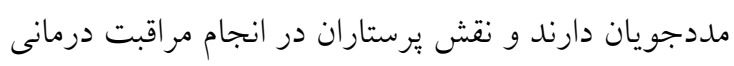
با كيفيت براى مددجويان، مهم در نظر كرفته مى مدئسود (10).

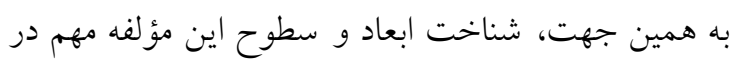

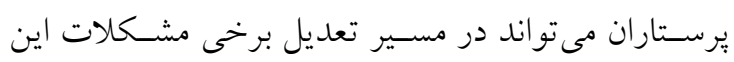

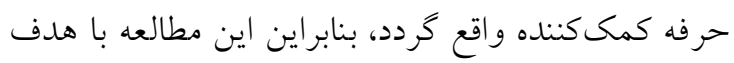

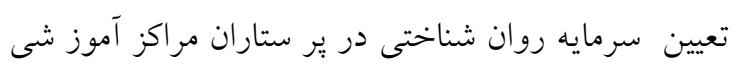

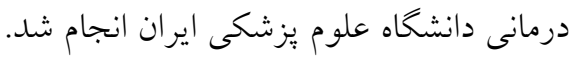

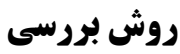

اين بُزوهش يك مطالعه توصيفى بود كه در آن سرمايه

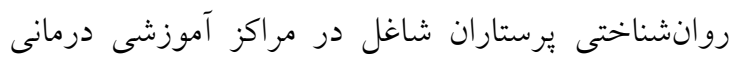

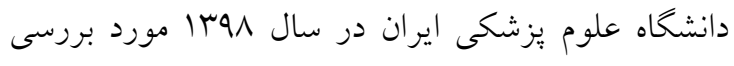

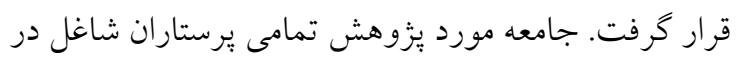

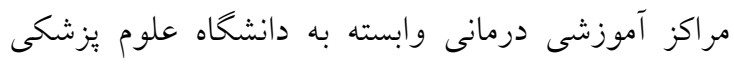




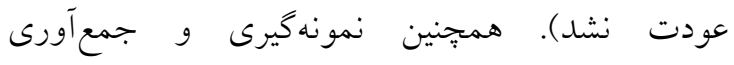
يرسشنامها به دليل مشغله كارى يرستاران حدود ينج ماه

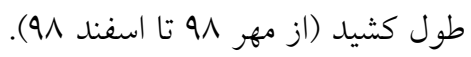
تحليل داده با استفاده از نرم|فزار SPSS نسخه 17 در در دول

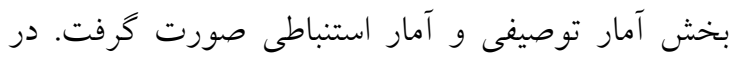

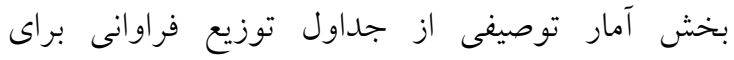
متغيرهاى كيفى ئزوهش و شاخصهاى عددى كمينه،

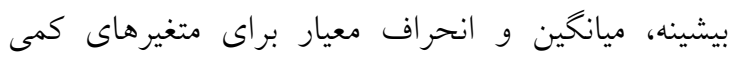

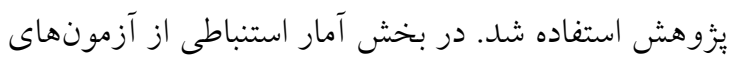

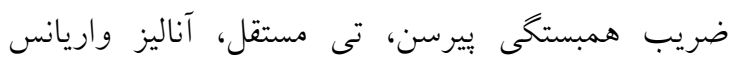

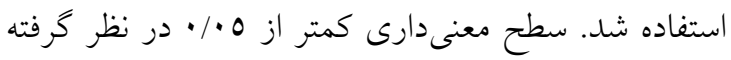

\section{يافتهها}

ميانخين سن افراد مورد يزّوهش وافها

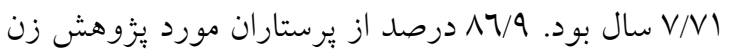
بودند و تحصيلات كارشناسى با 17/7 درصد بيشترين سطح تحصيلى در بين سطوح تحصيلى بود. اكثر برستاران

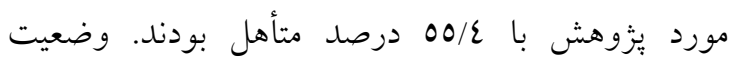
اقتصادى VN/V درصد در حد متوسط بود و 19/1 درصد

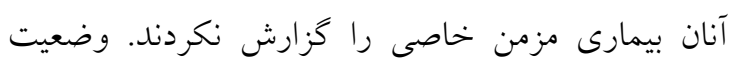

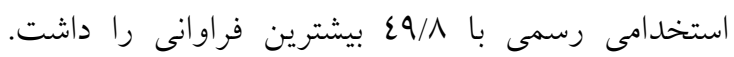

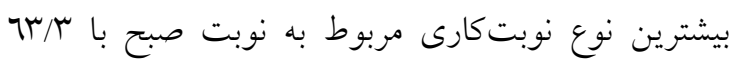

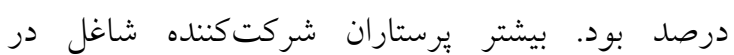

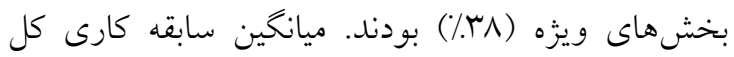

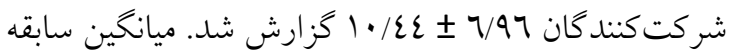

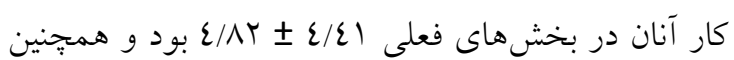

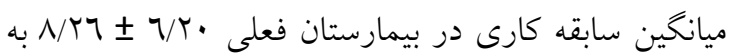
دست آمد (جدول شماره ()).
تأهل، وضـعيت اسـتخدامى، تحصـيلات، سـابقه كارى،

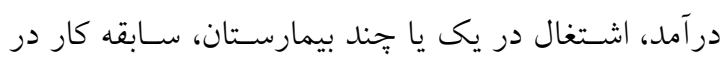
بخش فعلى، سابقه كار در بيمارستان فعلى سمت كارى و

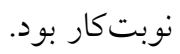

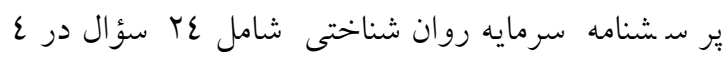

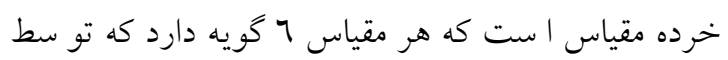
Luthans

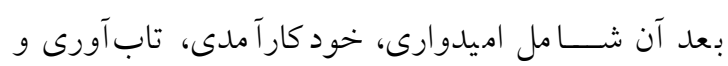

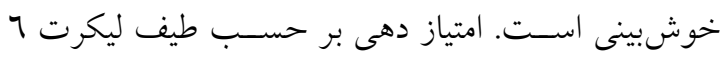

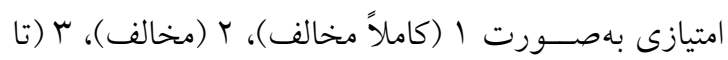

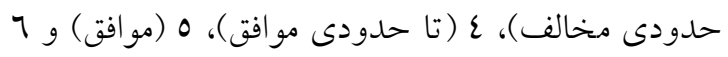

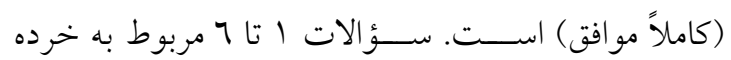

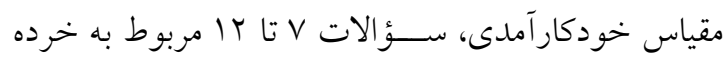

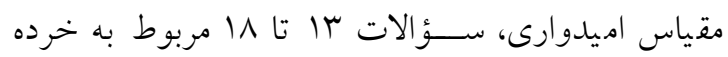

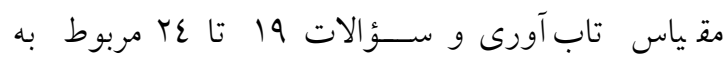

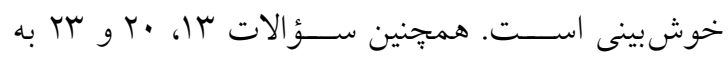

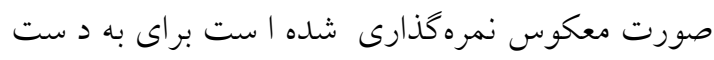

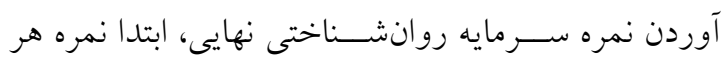

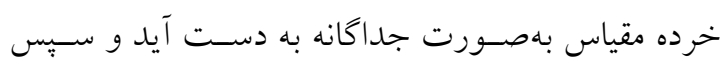

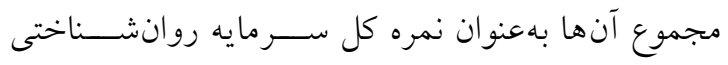

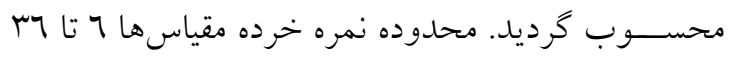

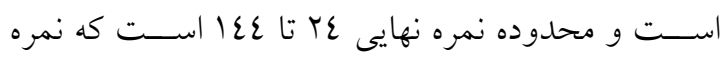
بالاتر نشـاندهنده سـرمايه روانشـناختى قوى و نيرومند

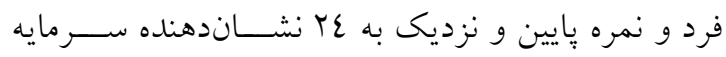

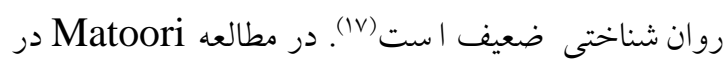

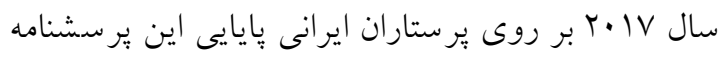

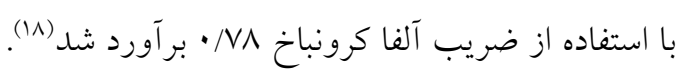
محقق در صورت لزوم و براى كاهش محدوديت ناشى از مشغله كارى؛ میع ساعت بعد يا در بايان نوبتكارى

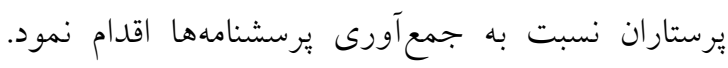

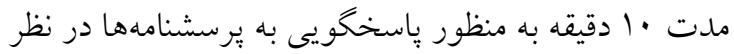

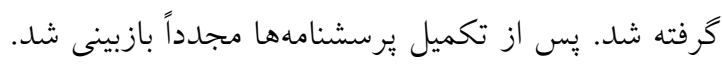

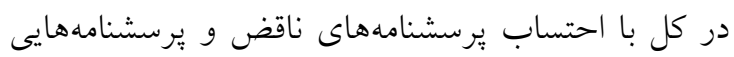

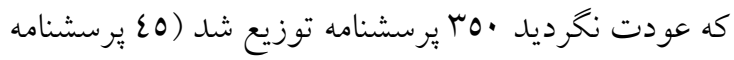


جدول شماره ا: شاخصهاى عددى سرمايه روانشناختى برستاران شاغل در مراكز آموز شى درمانى دانشًاه علوم بزشكى ايران بر حسب

\begin{tabular}{|c|c|c|c|c|c|}
\hline \multirow{3}{*}{ نتيجه آزمون } & & & & \multicolumn{2}{|c|}{ مشخصات فردى و شغلى سال 11991 } \\
\hline & \multicolumn{2}{|c|}{ سرمايه روانشناختى } & \multirow[t]{2}{*}{ فراوانى (درصد) } & \multicolumn{2}{|c|}{ مشخصات فردى و شغلى } \\
\hline & انحر اف معيار & ميانگين & & & \\
\hline$" F=1, r \varepsilon$ & $\mid r / 0 r$ & $1 . \varepsilon / 77$ & $(r \cdot / 0) q r$ & كمتر از •r & \\
\hline \multirow[t]{3}{*}{$\mathrm{P}=\cdot / \pi q \varepsilon$} & $17 / 0$. & $1 . \varepsilon / 11$ & $(\varepsilon r / r) \mid r q$ & $r \cdot-r q$ & سن (سال) \\
\hline & $10 / \mathrm{Va}$ & $1 \cdot \varepsilon / T V$ & $(T \Gamma / Q) V \Gamma$ & $\varepsilon \cdot-\varepsilon q$ & \\
\hline & $0 / 00$ & $11 r / v$ & $(r / \Gamma) 1 \cdot$ & 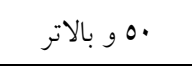 & \\
\hline${ }^{* * *} \mathrm{t}=-\cdot / 771 \quad \mathrm{df}=r \cdot r$ & $10 / 00$ & $1 \cdot \varepsilon / \varepsilon 1$ & $(\Lambda 7 / 9) \times 70$ & زن & 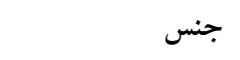 \\
\hline$P=\cdot / 0 \cdot 9$ & $\mid r / T \varepsilon$ & $1.7 / / r$ & $(\mid r / 1) \varepsilon$ & مرد & \\
\hline$* * t=-1 / r 0 \quad d f=r \cdots$ & $10 / 2 Y$ & $1 . \varepsilon / 11$ & $(\Lambda \nearrow / 7) Y\urcorner \varepsilon$ & كارشناسى & تحصيلات \\
\hline $\mathrm{P}=\cdot / r 11$ & $\mid r / 7 V$ & $1 \cdot V / \Omega r$ & $(I T / 0) \mu \wedge$ & كارشناسى ارشد & \\
\hline$* \mathrm{~F}=\cdot / \varepsilon / \varepsilon$ & $\mid r / 2 \Lambda$ & $1.0 / 27$ & $(r \cdot / V) 7 r$ & طرحى & \\
\hline \multirow[t]{4}{*}{$\mathrm{P}=\cdot /$ / $\wedge$ } & $10 / 41$ & $1.1 / 9 \mathrm{~V}$ & $(\mid r / 0) \mu_{\Lambda}$ & ي ييمانى & وضعيت استخدامى \\
\hline & $10 / 11$ & $1 \cdot \varepsilon / \cdot 9$ & $(7 / 9) r 1$ & 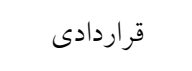 & \\
\hline & $\mid r / 7 V$ & $1 \cdot r / \Lambda$ & $(1 \cdot / r) \mu 1$ & 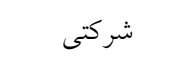 & \\
\hline & $17 / \pi r$ & $1.0 / \pi$ & $(\Sigma 9 / 1) 10 r$ & رسمى & \\
\hline$* * t=\cdot N r T d f=r .$. & $17 / 91$ & $1.0 / 40$ & $(\varepsilon r / \tau) \mid r \mu$ & مجرد & وضعيت تأهل \\
\hline $\mathrm{P}=\cdot / \varepsilon 7 \varepsilon$ & $1 r / 94$ & $1 . \varepsilon / .0$ & $(00 / 2) 179$ & 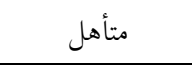 & \\
\hline ***t=l/or $\quad \mathrm{df}=r \cdot r$ & $\mid r / T r$ & $1 \cdot v / \cdot v$ & $(T r / r) V I$ & ثابت & نوبت كارى \\
\hline $\mathrm{P}=\cdot / / r_{0}$ & $10 / 9 r$ & $1 . r / \Lambda 9$ & $(V T / V) r \mu \varepsilon$ & در كردش & \\
\hline$* \mathrm{~F}=\cdot / r \cdot r$ & $10 / 70$ & $1.0 / .1$ & $(7 T / r) 19 \%$ & صبح & \\
\hline \multirow[t]{2}{*}{$\mathrm{P}=\cdot / 1 / 7$} & $1 \varepsilon / 0 V$ & $1 . \varepsilon / \pi q$ & $(Y T / M) V Y$ & عصر & نوع نوبت كارى \\
\hline & $1 \varepsilon / v q$ & $1 \cdot r / \varepsilon r$ & $(\mid r / 1) \varepsilon$. & شب & \\
\hline$* \mathrm{~F}=\Lambda / 7$ & $10 / \pi 9$ & $1 . r / 17$ & $(\Lambda ০ / Y) Y\urcorner$. & يرستار & \\
\hline \multirow[t]{3}{*}{$\mathrm{P}<\cdot / \cdot \cdot 1$} & $11 / 17$ & $11 r / 9$ & $(1 \cdot / r) r 1$ & 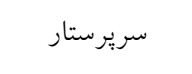 & سمت شغلى \\
\hline & 1.1 & $11 r / 7 \varepsilon$ & $(\varepsilon / 7) \backslash \varepsilon$ & سويروايزور & \\
\hline & $1 r / r q$ & $1 . r / \pi 7$ & $(r T / r) \wedge$. & عمومى(جنرال) & \\
\hline$* \mathrm{~F}=\cdot / \mathrm{ov} 0$ & $9 / 9 \varepsilon$ & $1 \cdot N / O V$ & $(7 / 9) Y I$ & داخلى & \\
\hline \multirow[t]{3}{*}{$\mathrm{P}=\cdot / 7 \curlywedge 1$} & $1 r / 9$ & $1 \cdot \varepsilon / v$ & $(10 / \varepsilon) \varepsilon V$ & جراحى & بخش كارى \\
\hline & $1 N / 1$ & $1 \cdot \varepsilon / \Gamma 1$ & $(r \Lambda) 117$ & ويزه & \\
\hline & $\mid \varepsilon / .0$ & $1.0 / 90$ & $(\mid r / \varepsilon) \varepsilon \mid$ & ساير س & \\
\hline$* \mathrm{~F}=\cdot / 77 \varepsilon$ & $1 \% / \wedge 9$ & $1 \cdot \varepsilon / \varepsilon \varepsilon$ & $(T V / 0) \wedge \varepsilon$ & كمتر از 0 & \\
\hline \multirow[t]{4}{*}{$\mathrm{P}=\cdot / 71 \wedge$} & IT/Tr & $1 \cdot r / \varepsilon$. & $(17 / 2) 0$. & $1 \cdot-0$ & سابقه كار (كل) \\
\hline & 11 & $1.0 / .7$ & $(r \varepsilon / T) V_{0}$ & $10-1$ & \\
\hline & $1 \varepsilon / 10$ & $1 . \varepsilon / 0 r$ & $(Y 1 / 7) 77$ & $r \cdot-10$ & \\
\hline & $10 / 70$ & $1 \cdot 1 / \cdot 7$ & $(9 / \Lambda) r \cdot$ & 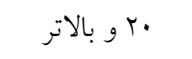 & \\
\hline$* \mathrm{~F}=\cdot / \cdot\urcorner \varepsilon$ & $10 / 90$ & $1 \cdot \varepsilon / \varepsilon 1$ & $(7 \cdot / \Gamma) \backslash \wedge \varepsilon$ & كمتر از 0 & سابقه كار در بخش \\
\hline \multirow[t]{2}{*}{$\mathrm{P}=\cdot / 9 \vee 9$} & $\mid r / 27$ & $1.0 / 2 r$ & $(I N / N) O V$ & $1 \cdot-0$ & فعلى، سال \\
\hline & $10 / 01$ & $1 \cdot\{/ 71$ & $(I V N)$ or & $10-1$. & \\
\hline
\end{tabular}




\begin{tabular}{|c|c|c|c|c|c|}
\hline & $11 / 11$ & $1 \cdot \varepsilon / \varepsilon$. & $(\Gamma / \mu) 1 \cdot$ & ا 10 و بالاتر & \\
\hline$* \mathrm{~F}=\cdot / \mathrm{V} \backslash \Lambda$ & $1 r / 7 V$ & $1 \cdot \varepsilon / \varepsilon 1$ & $(r v / \varepsilon) 111$ & كمتر از 0 & سابقه كار در \\
\hline \multirow[t]{3}{*}{$\mathrm{P}=\cdot / 0 \varepsilon r$} & $\mid r / N$ & $1 \cdot r / 91$ & $(10 / N) \varepsilon \wedge$ & $1 \cdot-0$ & بيمارستان فعلى، سال \\
\hline & IT/AY & $1 \cdot T / r V$ & $(T / \varepsilon) 1 \cdot r$ & $10-1$ & \\
\hline & $1 N / 1 \Lambda$ & $1 \cdot r / T V$ & $(1 \varepsilon / \varepsilon) \varepsilon \varepsilon$ & 10 10 & \\
\hline$* \mathrm{~F}=\cdot / 01 \mathrm{~V}$ & $1 \varepsilon / 90$ & $1 \cdot r / \wedge r$ & $(9 / \Lambda) \mu$. & ضعيف & \\
\hline \multirow[t]{2}{*}{$\mathrm{P}=\cdot / 09 \mathrm{~V}$} & $10 / 21$ & $1 \cdot \varepsilon / 07$ & $(V \wedge / V) T \varepsilon$. & متوسط & وضعيت اقتصادى \\
\hline & $1 \varepsilon / 7$. & $1 \cdot 7 / 70$ & $(11 / 0)$ ro & خوب & \\
\hline$* * t=-1 / 97 \quad \mathrm{df}=r \cdot r$ & $1 \varepsilon / 19$ & $99 / 0 \varepsilon$ & $(1 \cdot / r) r_{1}$ & 2 & بيمارى مزمن \\
\hline $\mathrm{P}=\cdot / \cdot 0$ & $\mid 0 / T 1$ & $1.0 / T_{1}$ & $(\wedge q / \Lambda) \Upsilon \vee \varepsilon$ & 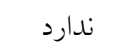 & \\
\hline
\end{tabular}

شده در سرمايه روانشناختى در يرستاران بهطور معنى دارى

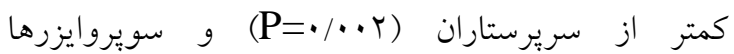

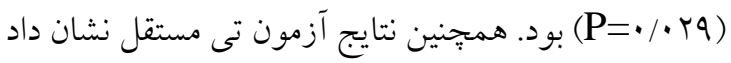
سرمايه روانشناختى با بيمارى مزمن نيز ارتباط معنى دارى

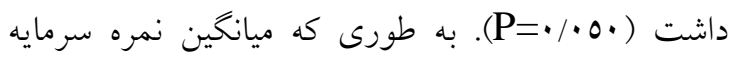
روانشناختى در برستارانى كه بيمارى مزمن داشتند به طور معنى متغيرهاى فردى و شغلى با سرمايه روانشناختى ارتباط معنى دار آمارى نداشت (0 • P> (P) (جدول شماره (1).

\section{بحث و نتيجه كيرى}

نتايج حاصل از تجزيه تحليل دادهها نشان داد كه ميانكين نمره ســرمايه روانشــاختى كل در برسـتاران 10/Y0 سج/ع •ا بود و با تو جه به دامنه نمره عب تا ععا در ير سمشنامه سرمايه روان شناختى و ميانحين نمره به د ست

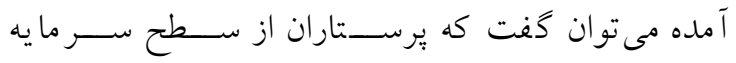
روانشــناختى تقريباً بالايى برخوردارند. همجِنين از بين ابعاد سرمايه روانشناختى برستاران مراكز آموزشى درمانى

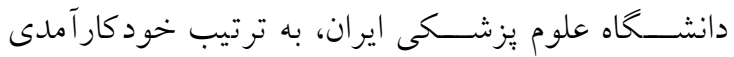
بيشـــترين و تابآورى كمترين ميانخين نمره را كســـبـ

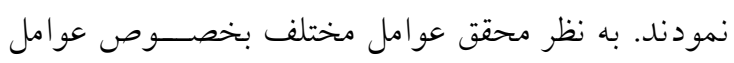
مرتبط با محيط كارى بر ستاران مانند باركارى زياد، كمبود نيروى انسـانى و جو محيط كارى بخصـوص با توجه به

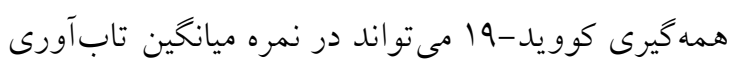

همانطور كه در جدول شماره Y مشاهده مى شود، از بين ابعاد سرمايه روانشناختى يرستار ان مراكز آموزشى درمانى دانشخاه علوم يز شكى ايران، بالاترين ميانخين نمره مربوط

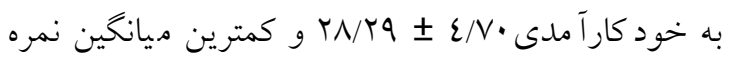

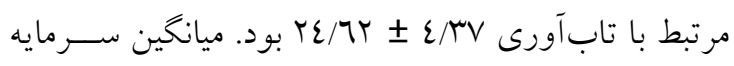

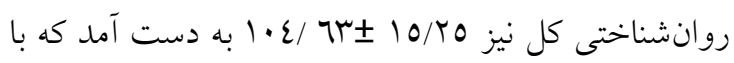

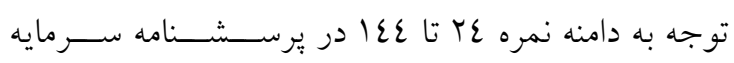
روانشـناختى و ميانخين نمره بهدسـتآ ملده مىتوان كفت

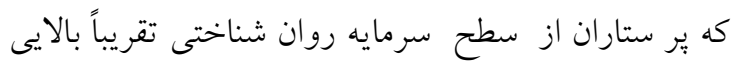
برخوردارند.

جدول شماره r: شاخصهاى عددى سرمايه روانشناختى

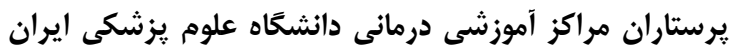

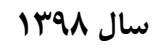

\begin{tabular}{|c|c|c|c|c|}
\hline انحر اف & ميانخين & بيشينه & كمينه & سرمايه روانشناختى \\
\hline$\varepsilon / V$. & $T \wedge / T q$ & ra & 7 & خود كار آمدى (7-7") \\
\hline $0 / 10$ & $r 7 / 09$ & ry & 7 & اميدوارى (ך-רץ) \\
\hline$\varepsilon / \mu V$ & $r \varepsilon / 7 r$ & r & 7 & تابآورى (7-7r) \\
\hline$\varepsilon / \mu_{1}$ & rO/IT & ry & 7 & خوش بينى (7-7ץ) \\
\hline $10 / T_{0}$ & $1 \cdot \varepsilon / 7 \pi$ & $1 \varepsilon \varepsilon$ & $r \varepsilon$ & سرمايه روانشناختى (ع كانعـا) \\
\hline
\end{tabular}

نتايج آناليز واريانس نشان داد سرمايه روانشناختى با سمت

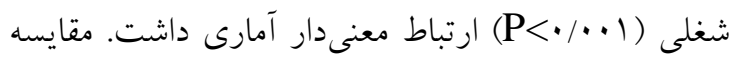

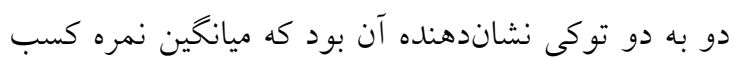


حاضــر مشــابه نبود كه در توجيه آن مىتوان به تفاوت

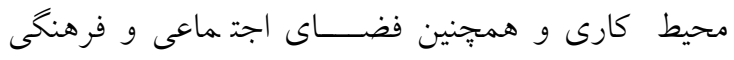

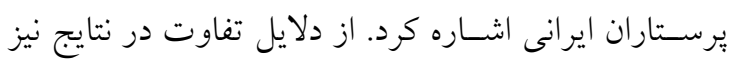

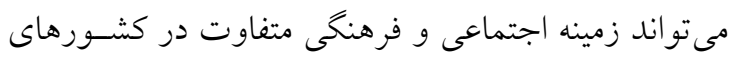
مختلف را ذكر نمود. همجنِين يافتهاى اين مطالعه در رابطه با ارتباط ســرمايه روانشناختى با متغيرهاى جمعيت شناختى ير ستاران نشان

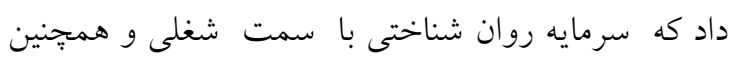

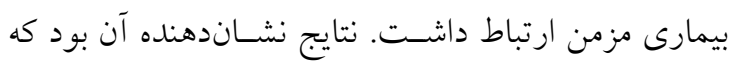

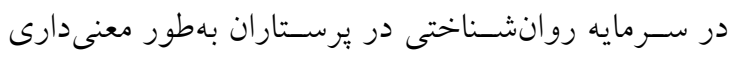

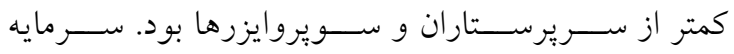
روانشـناختى در يرســتارانى كه بيمارى مزمن داشـتند به

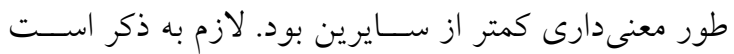

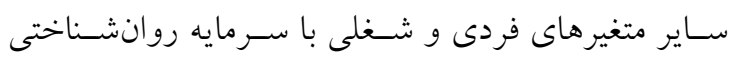

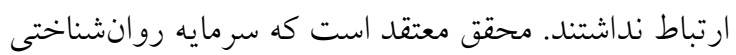

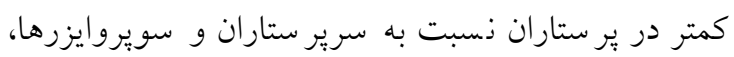

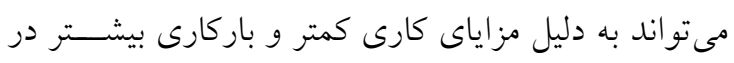

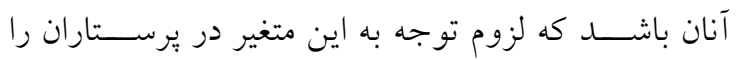

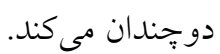
در مطالعه جعفرى زاده و همكاران تحت عنوان "ابعاد

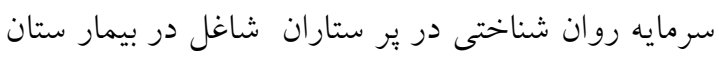

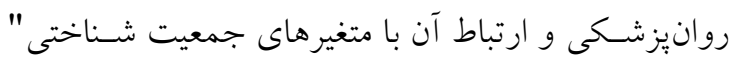

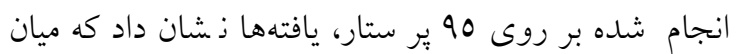

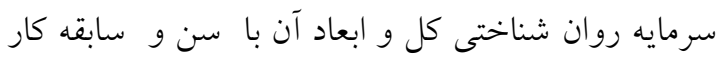
راب طه معنى دارى وجود ندارد. همجنين بين ســر ما يه

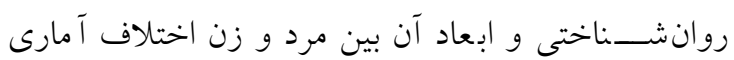

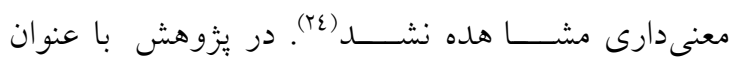

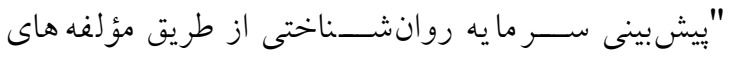

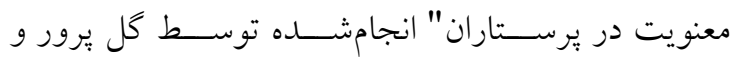

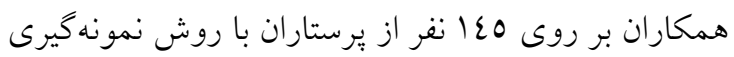

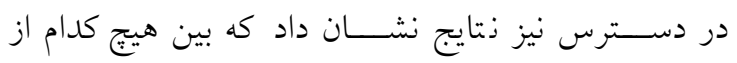
متغير هاى جمع يت شـــاختى و مؤلفه هاى ســـر ما يه ديه روانشناختى در يرستاران رابطه معنى دارى وجود ندارد (ro) كه همخى ناهم سو با مطالعه حاضر بودند. در توجيه نتايج روني

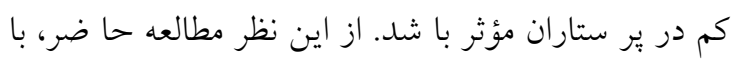
برخى يزوهش ها همسو بود. جعفرى زاده و همكاران در مططالعهاى بر روى 90 نفر از بردي

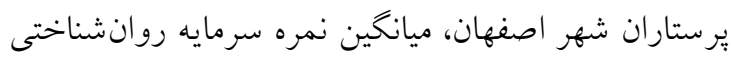

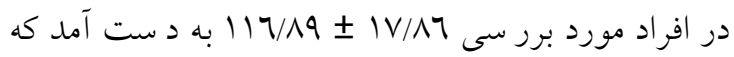
حاكى از بالا بودن سطح سرمايه روانشناختى در برستاران

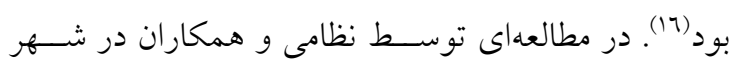

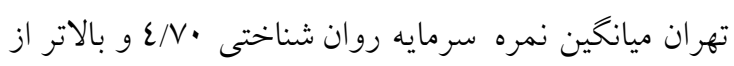

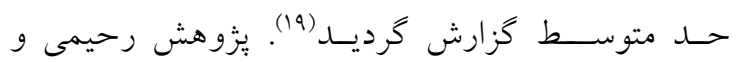

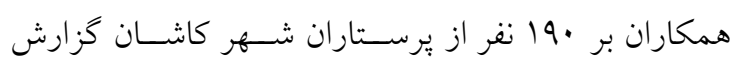

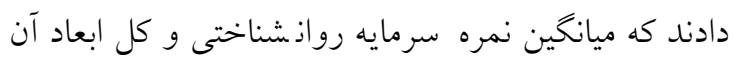

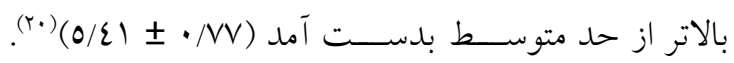

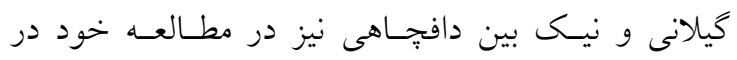

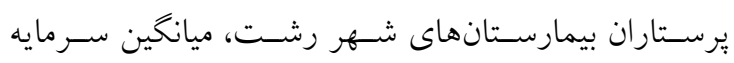

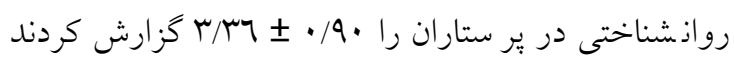

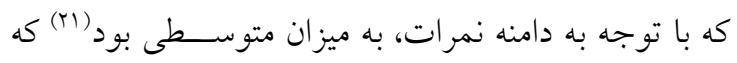

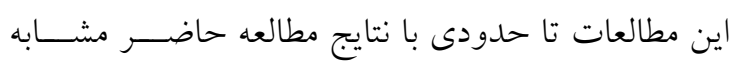

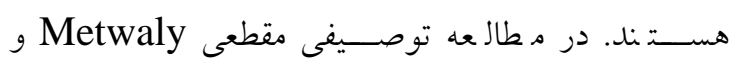

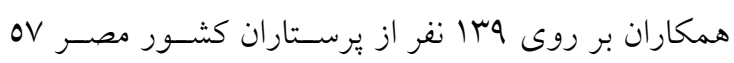

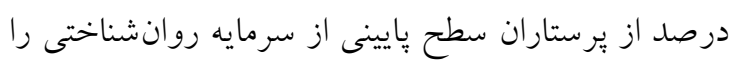

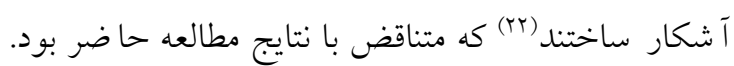
در توجيه نتايج همسـو مىتوان به شـرايط حاكم بر محيط

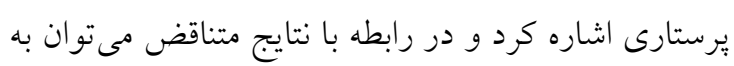
تفاوتهاى فردى و اجتماعى / فرهنكى اشاره كرد.

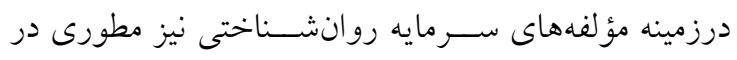

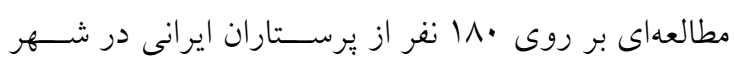
تهران بيشــرين ميانخين نمره در بين مؤلفههاى ســـرمايه

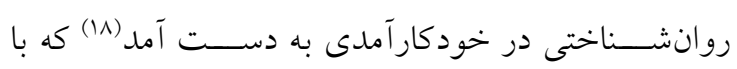

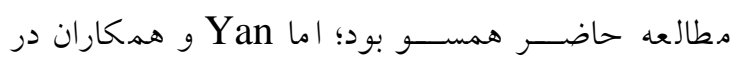
مطالعهاى در كشور جين تحت عنوان "ارتباط ميان سرمايه

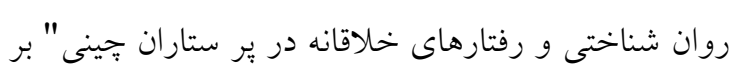

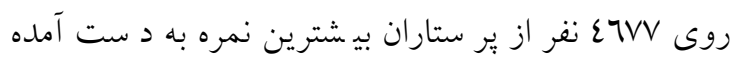

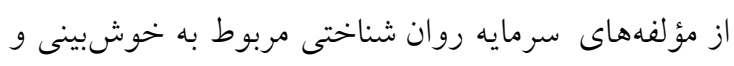

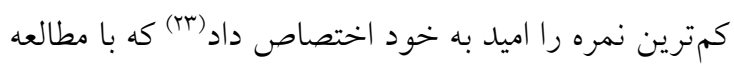


لازم در اين حيطه مى توان مقد مات ارتقا در عملكرد

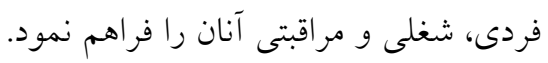

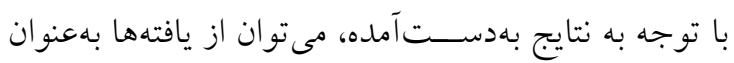

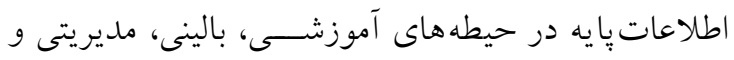

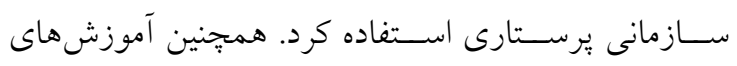

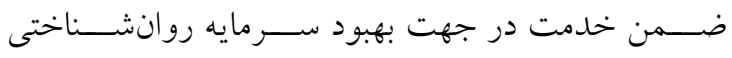

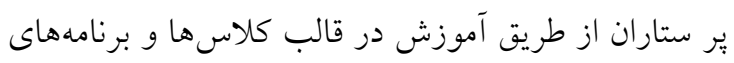
مدون بر روى برسـتاران عملى اســت. نتايج اين مطالعه مى تواند سياست كذاران حيطه سلامت و درمان را در زمينه تدوين برنامههاى متمركز بر بهبود سلامت روان بر ستاران

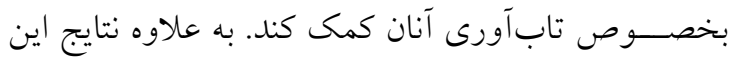
يثزوهش مىتواند در زمينه آموزش يرسـتارى كمككننده

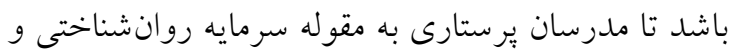

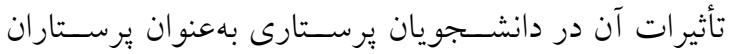
آينده تمركز و توجه بيشترى نمايند.

تعارض منافع: هيج كونه تعارض منافع توسط نويسندكان

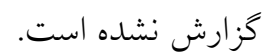

\section{تقدير و تشكر}

محقق از مسئولان بيمارستانى و يرستاران مراكز آموزشى

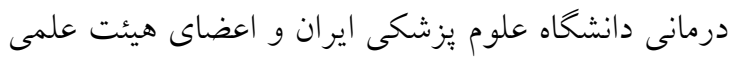

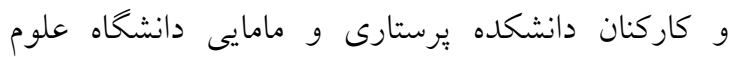
يزشكى ايران تشكر و قدردانى مىنمايد. اين مقاله حاصل باياننامه كارشناسى ارشد در رشته روان برستارى دانشخاه علوم بزشكى ايران است.
ناهمسو مىتوان به مواردى همجيون بخش كارى يرستاران،

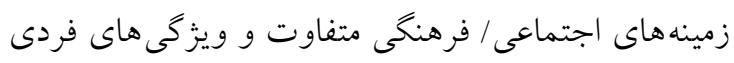

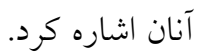
در كل بر اساس نتايج اين مطالعه، يرستاران از سطح سرمايه روانشناختى تقريباً بالايى برخوردار بودند. محقق با مرور

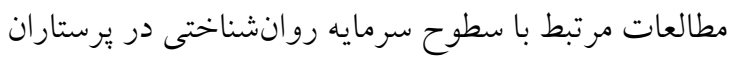
به نتايج مختلفى برخورد كرد كه در توجيه مى توان شباهت

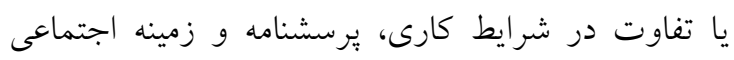

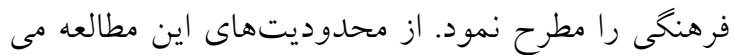
توان به مشغله ذهنى و باركارى فشرده برستاران اشاره كرد

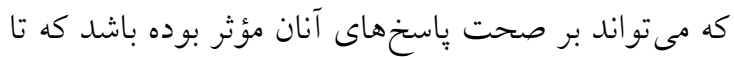
حد امكان سعى شد يرسشنامهها در آخر شيفت كارى آنان

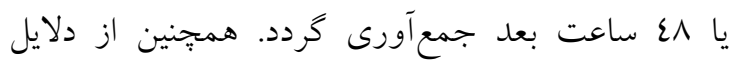
طولانى شدن مدتزمان نمونه گيرى مىتوان به همزمانى

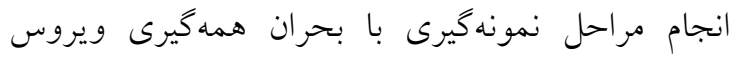

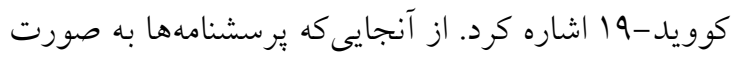

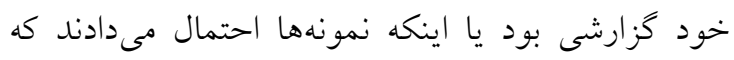

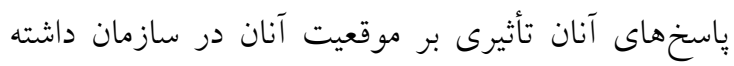

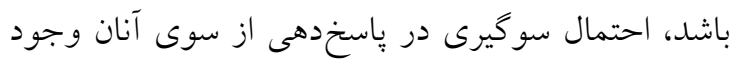

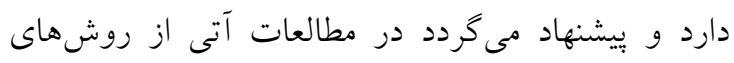
ديخرى همجيون مصاحبه و مشاهده استفاده شود.

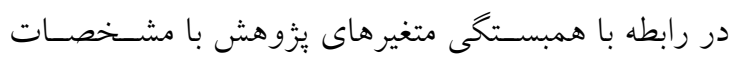

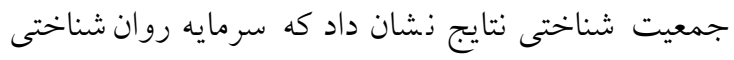
يرستاران كمتر از سريرستاران و سويروايزورها بود كه اين مورد اهميت يرداختن به سرمايه روانشناختى در يرستاران

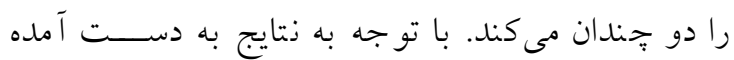

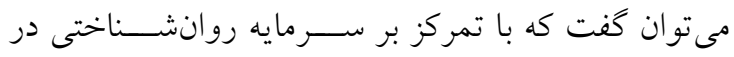

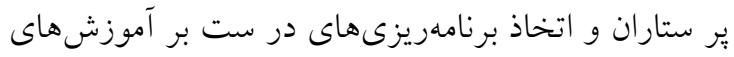




\section{References}

1. Kalantari M, Sajadi SA, Pishgooie SAH. Evaluation of nurses 'performance from nurses' viewpoints on providing safe care to patients in AjA hospitals in 2018. Military Caring Sciences Journal. 2019;5(3):173-81. [Persian]

2. Asheghi H, Asheghi M, Hesari M. Mediation Role of Psychological Capital Between Job Stress, Burnout, and Mental Health Among Nurses. Practice in Clinical Psychology. 2020;8(2):99-108. [Persian]

3. Hamed RA, Abd Elaziz SY, Ahmed AS. Prevalence and predictors of burnout syndrome, posttraumatic stress disorder, depression, and anxiety in nursing staff in various departments. Middle East Current Psychiatry. 2020;27(1):1-8.

4. Boamah S, Laschinger H. Engaging new nurses: The role of psychological capital and workplace empowerment. Journal of Research in Nursing. 2015;20(4):265-77.

5. Estiri M, Nargesian A, Dastpish F, Sharifi SM. The impact of psychological capital on mental health among Iranian nurses: considering the mediating role of job burnout. SpringerPlus. 2016;5(1):1-5.

6. Najjari R, Danayefard H, Hozoori MJ, Salehi A. Study and Explanation the Role of Psychological Capital on Organizational Outcomes. Scientific journal management system. 2013;1(2):23-36. [Persian]

7. Luthans F, Youssef CM, Avolio BJ. Psychological capital: Developing the human competitive edge. 2007.

8. Yadav G, Kumar S. Psychological capital: Moving towards building organizational strength. Ind J Posit Psychol. 2017;8(2):200-2.

9. Ghanenia M, Forouhar M, Jalili S. The Effect of Managers Psychological Capital Components Training on Increasing the Employees Engagement. Positive Psychology Research. 2015;1(3):5972. [Persian]

10. Makhlooq M, Simi Z, FathiMard F, Mohammadi M, Ghaderi S. The Relationship between Psychological Capital of Managers with Work Quality of Life of Nurses and Client Satisfaction in Semnan, Iran. Scientific Journal of Nursing, Midwifery and Paramedical Faculty. 2019;5(1):69-81. [Persian]

11. Matoori HH. Investigating the relationship between psychological capital and perceived organizational support with work engagement among nurses. Iran J Psychiatr Nurs. 2017;5(2):4551. [Persian]

12. Rahimi H, Baghsheykhi F, Azizi E, Haji Jafari S. Association of Psychological Capital and Job Adaptability in the Nurses of Kashan University of Medical Sciences Hospital, Iran. Iran Journal of Nursing. 2019;32(118):29-39. [Persian]

13. Idris AM, Manganaro M. Relationships between psychological capital, job satisfaction, and organizational commitment in the Saudi oil and petrochemical industries. J Human Behav Soc Environ. 2017;27(4):251-69.

14. Bao S, Taliaferro D. Compassion fatigue and psychological capital in nurses working in acute care settings. Int J Human Caring. 2015;19(2):35-40.

15. Estiri M, Nargesian A, Dastpish F, Sharifi SM. The impact of psychological capital on mental health among Iranian nurses: considering the mediating role of job burnout. SpringerPlus. 2016;5(1):1-5.

16. Jafarizadeh R, Sadeghi N, Azarbarzin M. Dimensions of Psychological Capital in the Nurses Employed in Psychiatric Hospitals and the Correlations with Demographical Variables. Iran Journal of Nursing. 2019;31(116):40-8. [Persian]

17. Luthans F, Youssef CM, Avolio BJ. Psychological capital: Developing the human competitive edge. New York: Oxford University Press; 2007.

18. Matoori HH. Investigating the relationship between psychological capital and perceived organizational support with work engagement among nurses. Iran J Psychiatr Nurs. 2017;5(2):4551. [Persian]

19. Nezami A, Givarian H. An investigation of the effect of psychological capital on the burnout of nurses in a military hospital in Tehran. EBNESINA. 2016;18(1):45-51. [Persian]

20. Rahimi H, Baghsheykhi F, Azizi E, Haji Jafari S. Association of Psychological Capital and Job Adaptability in the Nurses of Kashan University of Medical Sciences Hospital, Iran. Iran Journal of Nursing. 2019;32(118):29-39. [Persian] 
21. Nikbin Dafchahi Z, Hemmati Noedoust Gilani M. The Effect of psychological Capital on Nurses' performance with Regard to the Mediating Role of Burnout and Job Satisfaction. Research in Medical Education. 2021;13(1): 35-45. [Persian]

22. Metwaly SM, Ahmed H. The impact of psychiatric nurses' Psychological capital on their burnout and coping style. Egyptian Nursing Journal. 2018;15(3):302.

23. Yan D, Wen F, Li X, Zhang Y. The relationship between psychological capital and innovation behaviour in Chinese nurses. J Nurs Manag. 2020;28(3):471-9.

24. Jafarizadeh R, Sadeghi N, Azarbarzin M. Dimensions of Psychological Capital in the Nurses Employed in Psychiatric Hospitals and the Correlations with Demographical Variables. Iran Journal of Nursing. 2019;31(116):40-8. [Persian]

25. Golparvar M, Jafari M. Prediction of psychological capital through components of spirituality among nurses. Iranian journal of psychiatric nursing. 2013;1(3):35-44. [Persian] 